\title{
COMPRESSIVE BEHAVIOR OF CONCRETE FILLED GLASS FIBER REINFORCED POLYMER (GFRP) BOX PROFILES
}

\author{
Ferhat AYDIN* \\ Civil Engineering Department, Technology Faculty, Sakarya University, 54187 Sakarya, Turkey
}

\begin{abstract}
The use of concrete filled Fiber Reinforced Polymer (FRP) profiles for beams and columns has been studied extensively in recent years. Glass Fiber Reinforced polymers (GFRP) profiles are one of these materials. GFRP box profiles serve as formwork, and provide shear and flexural reinforcement in novel hybrid GFRP-concrete structural system. GFRP box profiles also protect the concrete and increase the strength of hybrid materials. This study presents results of an experimental study using concrete filled pultruded GFRP profiles. A series of compression tests were carried out to study the compression behavior of the proposed hybrid GFRP-concrete materials. Hybrid compression samples were fabricated and tested in three different strength classes. The results showed that compressive strength of hybrid material significantly increased when compared to reference samples.
\end{abstract}

Keywords: Composite; Hybrid material; Concrete; GFRP; Compressive strength

\section{INTRODUCTION}

New materials are developed due to material-related problems and the demands of users. Researchers investigate new material types and applications and try to produce new designs to address to these problems and to satisfy these demands. In recent years, many researchers have concentrated on composite materials and hybrid designs, which can be considered as a derivative of these materials. Composite materials have required properties and are preferred in a wide variety of fields including the construction sector. Fiber Reinforced Plastic (FRP) composites are one of these composite types [1] These new generation composite materials have drawn considerable attention due to their superior mechanical strength, lightweight structure, high corrosion resistance and high resistance to chemicals, electric insulation, low density and high resistance/density ratio [2-5]. On the other hand, since these materials are not adequately known by the users and researchers, they have not yet replaced other materials. In fact, it is estimated that FRP composites can be a good solution for the majority of existing applications [6]. FRP composites are currently used to repair and renovate the existing buildings and to construct new ones; they have been used in aircrafts and space industry for more than 50 years [7-8].

New generation composites are not generally considered to be used as bearing systems in construction industry; they are preferred as secondary construction elements. However, today they are also used as main construction elements. Particularly due to increased mass production of FRP composites, they began to be more effectively used in buildings for different purposes and the use of lightweight fiber reinforced composite materials with high resistance began to be widely used in strengthening, repair and renovation in concrete buildings [9]. Most common uses of these types of composite materials in combination with concrete include strengthening buildings by wrapping FRP laminates in bottom surfaces of beams and wrapping FRP fabrics on the entire surface [10-14]. Their uses range from strengthening rod and beam elements to wrapping of columns for seismic improvement. Furthermore, they have a wider field of use including strengthening walls, beams, plates, composite flying bridges. Hybrid designs which use FRP composites in combination with traditional construction materials and systems entirely consisting of composite profiles [15]. FRP materials have a wide field of application; 
they can be an alternative to conventional construction materials such as concrete, steel and wood [16]. Research, which used generally carbon and glass fiber FRP fabric or laminates with varying fiber contents will further gain impetus. These studies show that hybrid systems, which include a combination of profile FRP elements having bearing capacity and traditional construction materials such as concrete or steel will draw further attention [17-22].

The most recent research and development studies concentrated on hybrid systems, which use a combination of composite materials and conventional construction materials such as concrete [23]. There is a growing body of research on hybrid FRP columns formed by concrete filled or void FRP pipes [18]. A number of FRP-concrete hybrid systems have been developed over the years, including both open and closed FRP forms [24]. Much of previous research showed that combined use of FRP composites with conventional materials like concrete is one of the solutions to eliminate certain drawbacks and disadvantages caused by the use of construction elements completely made of FRP [25]. FRPs have shown a good cohesion with traditional construction materials such as wood, brick, concrete, steel and metal [26].

The present study was carried out in parallel to growing attention to fiber reinforced composites. The study analyzed hybrid use of concrete and GFRP composite box profiles, which are one of the popular materials of today. GFRP profiles have many superior properties. The improvements in compressive behavior of hybrid materials, which combines superior properties of GFRP with those of concrete, which is widely preferred and also has many advantages, have been analyzed. The studies in literature generally investigate tensile properties of hybrid materials. In the present study, we analyzed compressive behavior of hybrid construction elements formed by the combination of GFRP box profile and concrete.

\section{EXPERIMENTAL STUDIES}

Behavior of concrete and hybrid cube samples which were prepared at varying strengths (Figure 1) were analyzed in experimental studies. This sections contains two sub-chapters including material, which detailed the properties of GFRP-Concrete properties and compressive tests, which detailed experiment set-up.

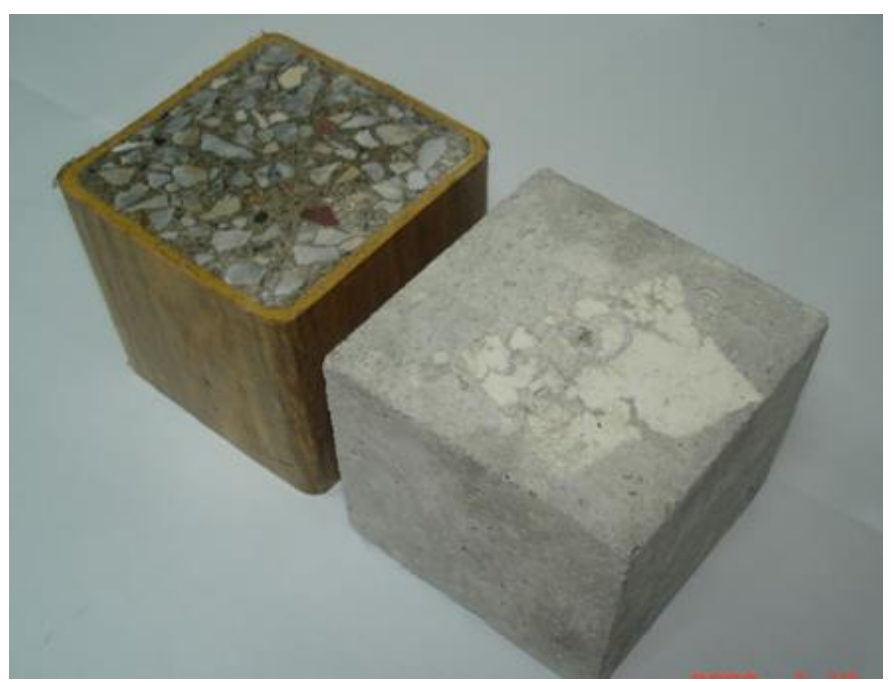

Figure 1. Concrete and hybrid compression samples 


\subsection{Material}

\subsubsection{GFRP Profiles}

Unit weight, fiber ratio and tensile properties of GFRP box profiles used in compressive tests were identified (Table 1). The samples were cut out from box profiles unit and specific weight tests were performed on the samples. Profile fiber ratios were determined using resin burning method [27]. Furthermore, modulus of elasticity and Poisson's ratios of GFRP materials were determined by tensile tests using related standards [28-30].

Table 1. Properties of GFRP

\begin{tabular}{|c|c|c|c|}
\hline Unit Weight & \multicolumn{3}{|c|}{$1.75 \mathrm{~g} / \mathrm{cm}^{3}$} \\
\hline Specific gravity & \multicolumn{3}{|c|}{1.80} \\
\hline Tensile Strength & \multicolumn{3}{|c|}{$560 \mathrm{~N} / \mathrm{mm}^{2}$} \\
\hline Modulus of elasticity (E) & \multicolumn{3}{|c|}{$29000 \mathrm{~N} / \mathrm{mm}^{2}$} \\
\hline Poisson Ratio & \multicolumn{3}{|c|}{0.34} \\
\hline Ratios Fiber of GFRP & Longitudinal & Felt & Matrix \\
\hline (\%) & 41.6 & 8.8 & 49.6 \\
\hline
\end{tabular}

The tests showed that GFRP had a unit weight of $1.75 \mathrm{~g} / \mathrm{cm}^{3}$ and specific weight of 1.80 . Modulus of elasticity, tensile strength and Poisson's ratio values of GFRP were found to be $29000 \mathrm{~N} / \mathrm{mm}^{2}, 560$ $\mathrm{N} / \mathrm{mm}^{2}$ and 0.34 respectively. Sample tensile and Poisson's ratio graphs of GFRP box profiles are presented in Figure 2 and Figure 3.

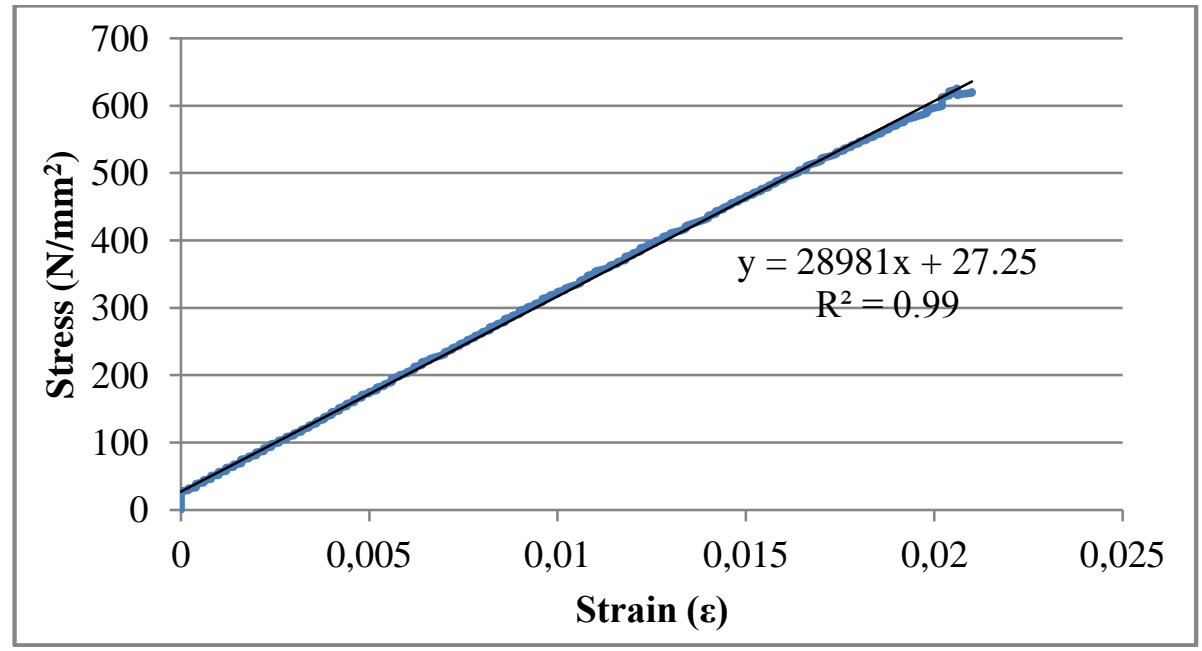

Figure 2. GFRP tensile chart 


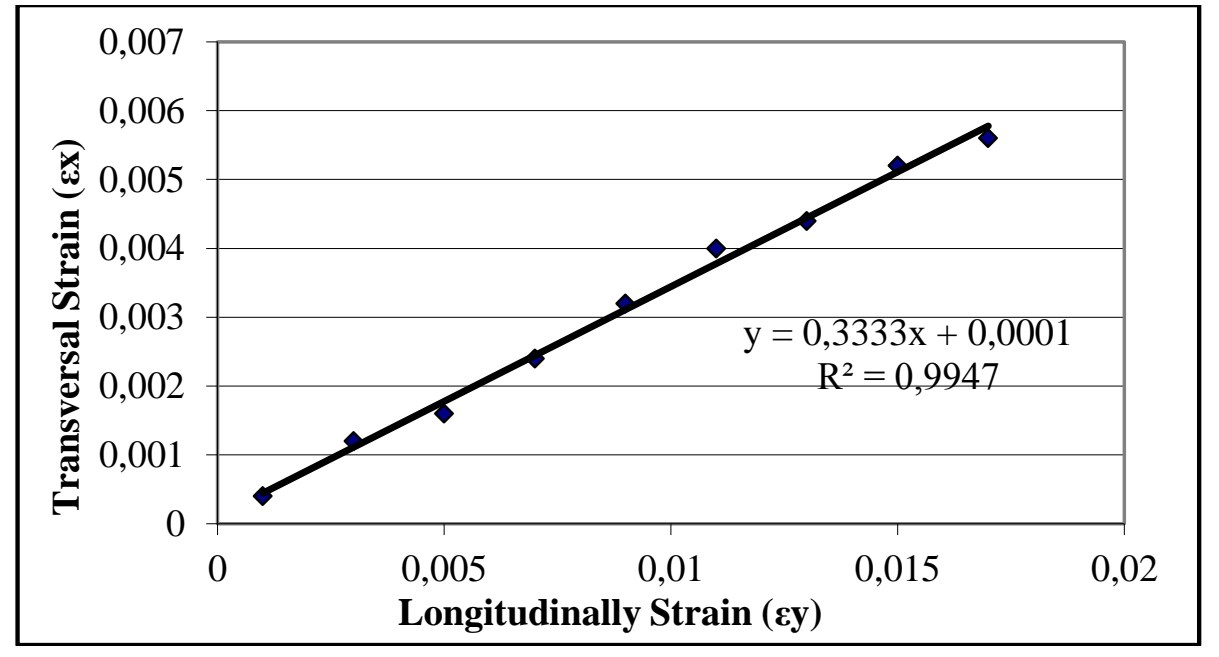

Figure 3. Poisson's ratio chart

\subsubsection{Concrete}

Mixture ratios in three different compressive strength classes were used to produce plain concrete and hybrid samples (Table 2). Only aggregate 1 was used as large aggregate to easily place the concrete inside GFRP profile.

Table 2. Mix proportions for $1 \mathrm{~m}^{3}$ concrete

\begin{tabular}{|l|c|c|c|}
\hline \multicolumn{1}{|c|}{ Material } & \multicolumn{3}{|c|}{ Strength Classes } \\
\hline \multicolumn{1}{|c|}{$\left(\mathrm{dm}^{3}\right)$} & I & II & III \\
\hline $\begin{array}{l}\text { Aggregates I } \\
(5-12 \mathrm{~mm})\end{array}$ & 379 & 381 & 382 \\
\hline Sand & 336 & 338 & 339 \\
\hline Cement & 105 & 111 & 119 \\
\hline Water & 170 & 158 & 146 \\
\hline Plasticizer & - & 2 & 4 \\
\hline Air & 10 & 10 & 10 \\
\hline Total & 1000 & 1000 & 1000 \\
\hline
\end{tabular}

Fresh concrete was produced by mixing materials at defined ratios. Some of the mixture was placed in molds, while the rest was placed in GFRP box profiles. Hardened hybrid and plain concrete cube samples were cured [31 and 32] prepared for compressive tests. Hybrid samples which were produced as beams were cut into cube size at the end of curing procedure.

\subsection{Compressive Tests}

Compressive tests were performed on 100x100x100 mm hybrid and plain concrete samples at three different compressive strength classes (Figure 4). Wall thickness of GFRP box profiles is $6 \mathrm{~mm}$. The results of the tests were evaluated and compared to the samples of the same type. 

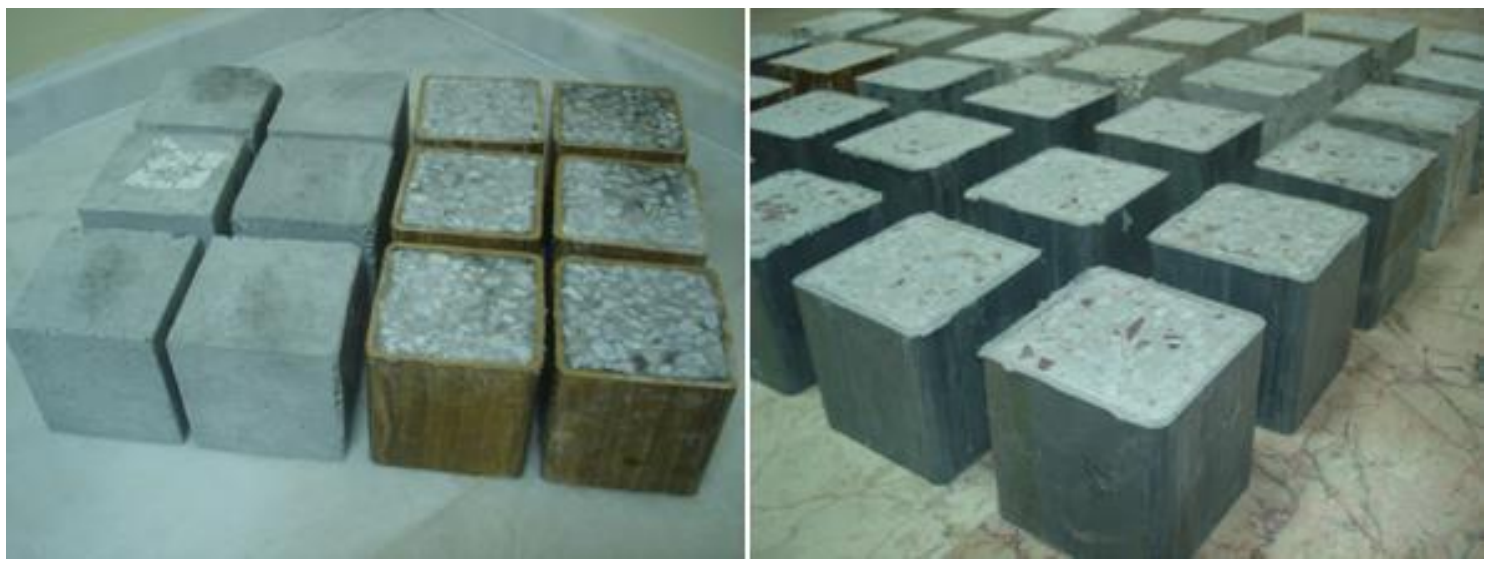

Figure 4. Compression samples

\subsubsection{Test Setup}

Computerized compression press with a capacity of 300 tons, digital displacement meter and data logger was used to measure the deformations in the material. Data logger had a total of 12 channels (4 and 8), can measure at the interval of \pm 10 volt and can record 8 data in a second. Digital displacement meter can measure at an interval of 0-50 $\mathrm{mm}$ and has a sensitivity of $0.01 \mathrm{~mm}$ (Figure 5).
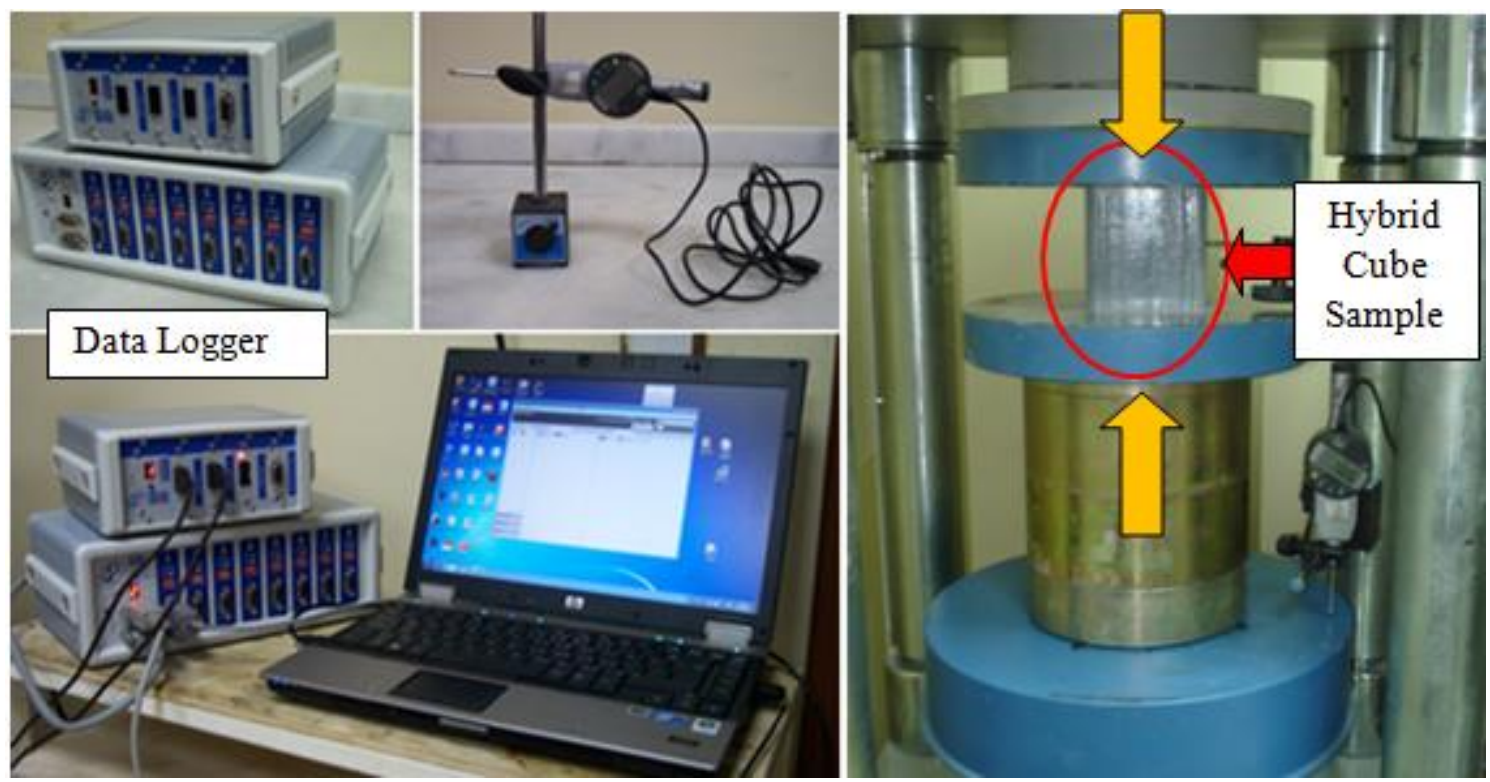

Figure 5. Test setup

\section{RESULTS AND DISCUSSION}

10 samples in each strength group, making a total of 30 plain concrete and hybrid cube samples were tested and compared according to tensile unit deformation graphs. Firstly, fracture loads, compressive strength and unit weights of compression samples in I. strength class were calculated and presented in Table 3 .

Mean fracture load of concrete samples in this strength class was found to be approximately $210000 \mathrm{~N}$, compressive strength was found to be $19.13 \mathrm{MPa}$ and unit weight value was found to be $2.30 \mathrm{~g} / \mathrm{cm}^{3}$. 
Mean fracture load of hybrid samples was found to be $350000 \mathrm{~N}$ approximately, compressive strength was found to be $33.11 \mathrm{MPa}$ and unit weight was found to be $2.22 \mathrm{~g} / \mathrm{cm}^{3}$. Comparison graph for the samples that represent the samples produced in I. strength class is presented in Figure 6.

Table 3. Compression test results in strength class I

\begin{tabular}{|c|c|c|}
\hline \multicolumn{3}{|c|}{ Plain Concrete Compressive Test Results } \\
\hline Sample & Compressive Strength (MPa) & Unit Weight $\mathbf{( g / \mathbf { c m } ^ { \mathbf { 3 } } )}$ \\
\hline 1 & 18.24 & 2.32 \\
\hline 2 & 20.12 & 2.28 \\
\hline 3 & 18.53 & 2.29 \\
\hline 4 & 20.32 & 2.32 \\
\hline 5 & 18.46 & 2.31 \\
\hline Average & $\mathbf{1 9 . 1 3}$ & $\mathbf{2 . 3 0}$ \\
\hline \multicolumn{3}{|c|}{ Hybrid Compressive Test Results } \\
\hline 1 & 32.04 & 2.23 \\
\hline 2 & 30.34 & 2.21 \\
\hline 3 & 34.58 & 2.24 \\
\hline 4 & 35.42 & 2.22 \\
\hline 5 & 33.18 & 2.21 \\
\hline Average & $\mathbf{3 3 . 1 1}$ & $\mathbf{2 . 2 2}$ \\
\hline
\end{tabular}

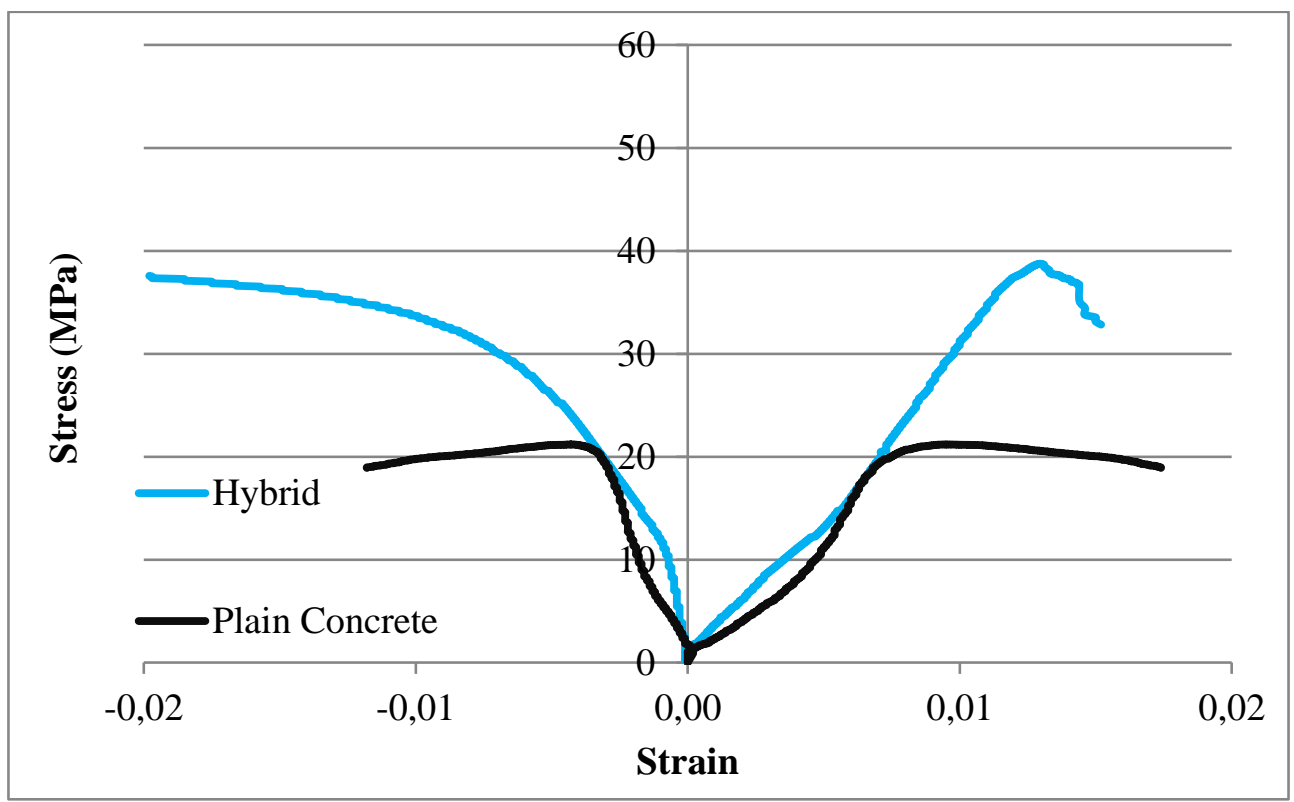

Figure 6. Comparison of stress-strain graphs in strength class I

The results showed that compressive strength of hybrid samples increased by $73 \%$ when compared to the plain concretes at the same cross sectional properties. While plain concrete cube samples had a unit deformation ratio of $1.7 \%$; hybrid samples had a unit deformation ratio of $1.5 \%$. Hybrid samples also function to protect the concrete, and serve as permanent mold and as an insulator. Plain concrete samples had a unit weight of $2.30 \mathrm{~g} / \mathrm{cm}^{3}$, while the hybrid samples had a unit weight of $2.22 \mathrm{~g} / \mathrm{cm}^{3}$. Thus, compressive strength of hybrid material increased, while its weight decreased by $4 \%$. 
Test results of the samples prepared in II. strength class are presented in Table 4.

Table 4. Compression test results in strength class II

\begin{tabular}{|c|c|c|}
\hline \multicolumn{3}{|c|}{ Plain Concrete Compressive Test Results } \\
\hline Sample & Compressive Strength (Mpa) & Unit Weight $\mathbf{( g / \mathbf { c m } ^ { \mathbf { 3 } } )}$ \\
\hline 1 & 26.84 & 2.31 \\
\hline 2 & 28.53 & 2.35 \\
\hline 3 & 28.05 & 2.32 \\
\hline 4 & 30.64 & 2.29 \\
\hline 5 & 29.28 & 2.32 \\
\hline Average & $\mathbf{2 8 . 6 7}$ & $\mathbf{2 . 3 2}$ \\
\hline & Hybrid Compressive Test Results \\
\hline 1 & 43.58 & 2.24 \\
\hline 2 & 47.16 & 2.21 \\
\hline 3 & 44.25 & 2.24 \\
\hline 4 & 42.37 & 2.23 \\
\hline 5 & 46.26 & 2.23 \\
\hline Average & $\mathbf{4 4 . 7 2}$ & $\mathbf{2 . 2 3}$ \\
\hline
\end{tabular}

Mean fracture load, compressive strength and unit weight of plain concrete samples were found to be approximately $300000 \mathrm{~N}, 28.67 \mathrm{MPa}$ and $2.32 \mathrm{~g} / \mathrm{cm}^{3}$ respectively. Mean fracture load value, compressive strength and unit weight values of hybrid samples were found to be approximately 460000 $\mathrm{N}, 44.72 \mathrm{MPa}$ and $2.23 \mathrm{~g} / \mathrm{cm}^{3}$ respectively. Comparison graph for the samples in II. strength class are presented in Figure 7.

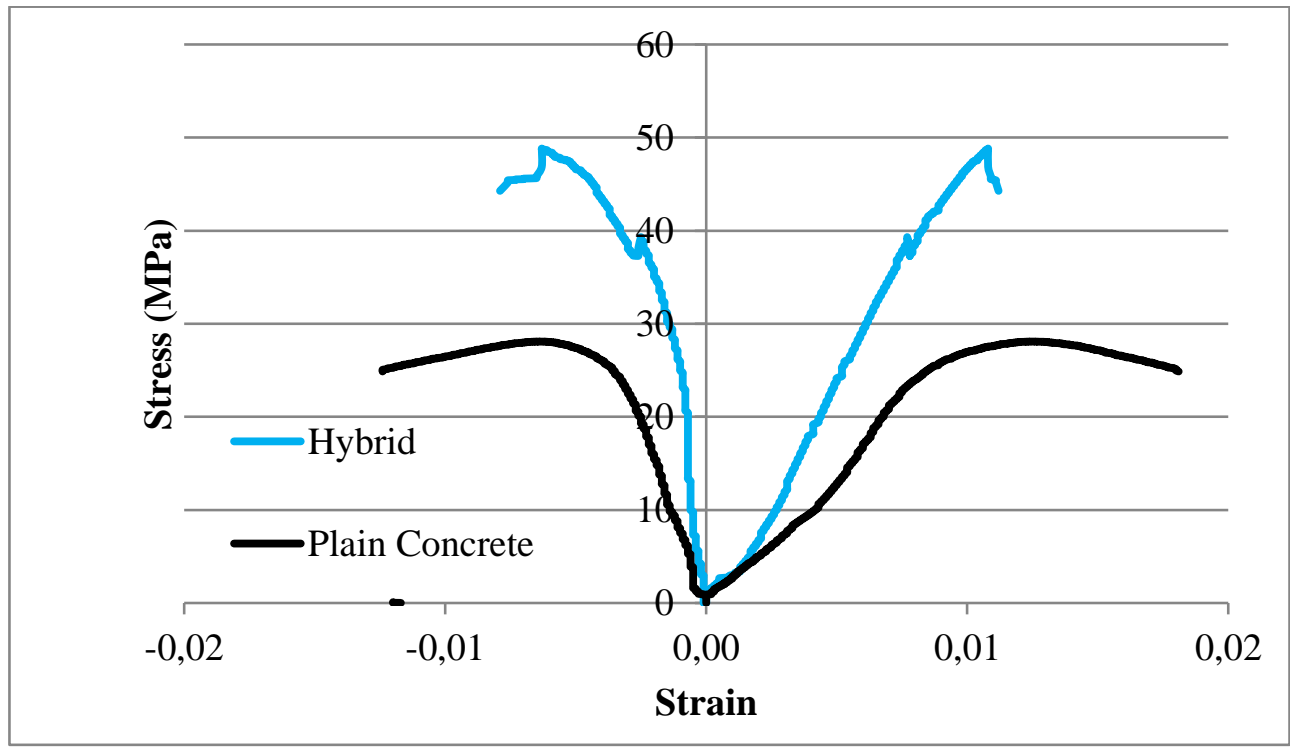

Figure 7. Comparison of stress-strain graphs in strength class II

Plain concrete cube samples in II. strength class had a unit deformation value of $1.5 \%$; while hybrid samples had a unit deformation value of $1.0 \%$. As the strength increased, the material became brittle. 
Based on these results, compressive strength of hybrid samples increased by $56 \%$ when compared to that of plain concrete samples. It was found that plain concrete samples and hybrid samples had a unit weight of $2.32 \mathrm{~g} / \mathrm{cm}^{3}$ and $2.23 \mathrm{~g} / \mathrm{cm}^{3}$ respectively. Thus, compressive strength of the material increased, however its weight decreased by $4 \%$.Compressive test results of the samples in III. strength class are presented in Table 5.

Tablo 5. Compression test results in strength class III

\begin{tabular}{|c|c|c|}
\hline \multicolumn{3}{|c|}{ Plain Concrete Compressive Test Results } \\
\hline Sample & Compressive Strength (MPa) & Unit Weight $\left(\mathbf{g} / \mathbf{c m}^{\mathbf{3}}\right)$ \\
\hline 1 & 42.67 & 2.38 \\
\hline 2 & 43.38 & 2.36 \\
\hline 3 & 42.82 & 2.34 \\
\hline 4 & 39.96 & 2.35 \\
\hline 5 & 44.64 & 2.35 \\
\hline Average & $\mathbf{4 2 . 6 9}$ & $\mathbf{2 . 3 6}$ \\
\hline \multicolumn{3}{|c|}{ Hybrid Compressive Test Results } \\
\hline 1 & 50.37 & 2.26 \\
\hline 2 & 51.18 & 2.25 \\
\hline 3 & 52.53 & 2.25 \\
\hline 4 & 49.32 & 2.26 \\
\hline 5 & 53.18 & 2.28 \\
\hline Average & $\mathbf{5 1 . 3 2}$ & $\mathbf{2 . 2 6}$ \\
\hline
\end{tabular}

It was found that fracture load, compressive strength and unit weight values of plain concrete samples were $420000 \mathrm{~N}, 42.69 \mathrm{MPa}$ and $2.36 \mathrm{~g} / \mathrm{cm}^{3}$ respectively. On the other hand, fracture load, compressive strength and unit weight values of hybrid samples were found to be $510000 \mathrm{~N}, 51.32 \mathrm{MPa}$ and 2.26 $\mathrm{g} / \mathrm{cm}^{3}$ respectively. Tensile-unit deformation graph which represents hybrid and concrete samples in III. strength class are presented in Figure 8.

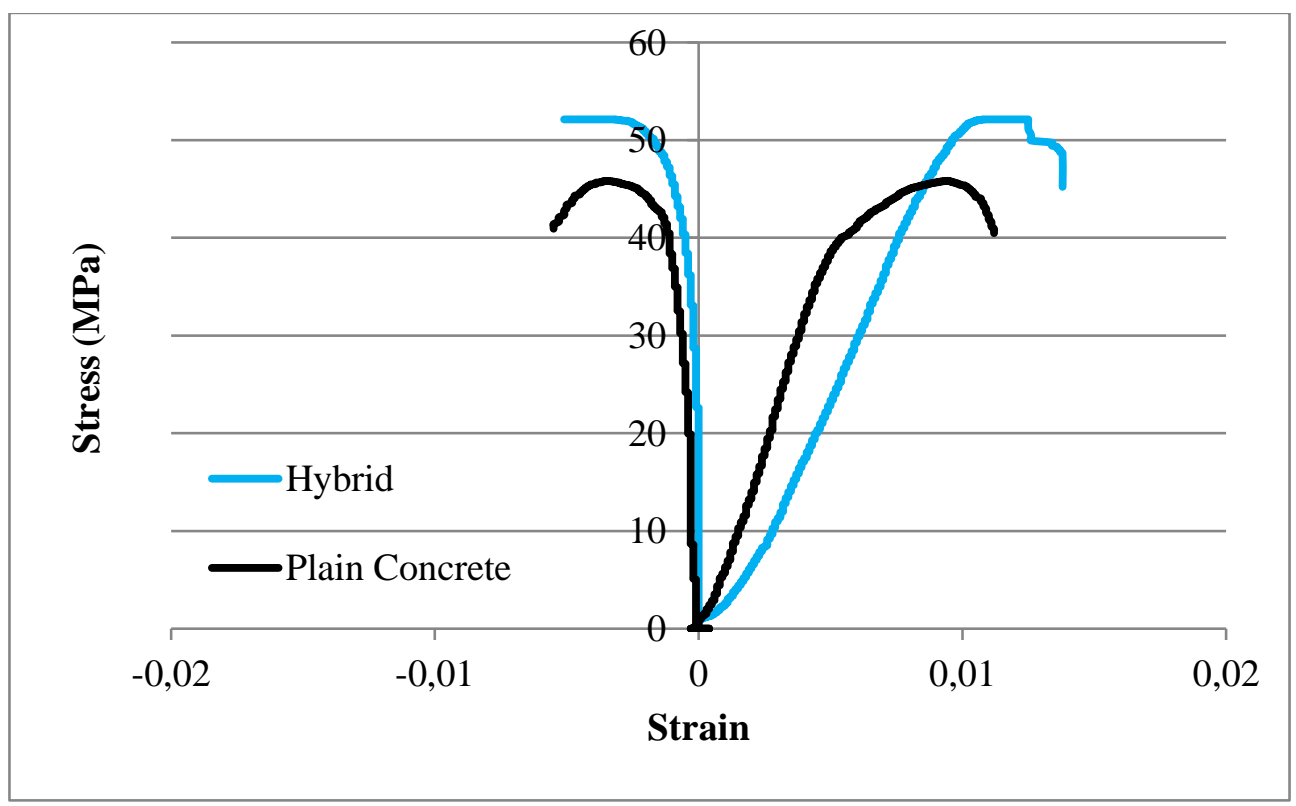

Figure 8. Comparison of stress-strain graphs in strength class III 
Compressive strength of hybrid samples increased by $20 \%$ when compared to that of plain concrete samples. It was found that as strength class of plain concrete samples increased, deformation decreased. While concrete samples had a unit weight of $2.36 \mathrm{~g} / \mathrm{cm}^{3}$, this value was found to be $2.26 \mathrm{~g} / \mathrm{cm}^{3}$ in hybrid samples. Compressive strength of the material increased by $20 \%$ and the weight of the material decreased by $5 \%$.

The ductility is decreased while the concrete strength class is increased in all specimens. The graph showing compressive strength increase in hybrid and plain concrete samples at all strength classes is presented in Figure 9. It is understood from the graph that in all compressive strength types, hybrid samples reached higher compressive strength values than those of plain concrete samples at a higher strength class. GFRP profiles do not allow the concrete lateral displacement thus the compressive strength of hybrid samples are greatly increased.

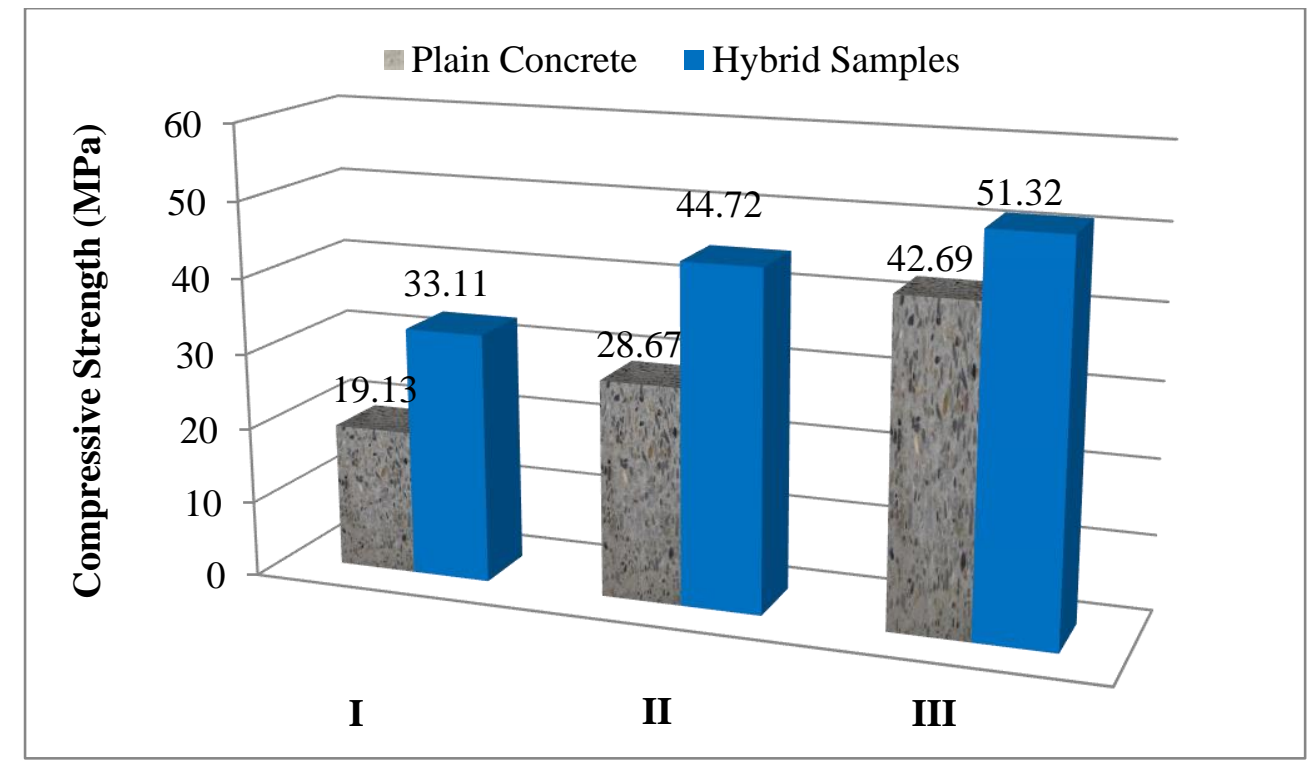

Figure 9. Comparison of compressive strength

Analysis of the samples in all strength classes showed that as compressive strength class increased, strength difference between hybrid and plain concrete samples decreased (Figure 10). It was found that in samples with a mean compressive strength of $22 \mathrm{MPa}$, increase rate started from $75 \%$ level in hybrid samples when compared to plain concrete samples. We found that as strength class increased, increase rate decreased. An increase of $20 \%$ occurred at $43 \mathrm{MPa}$ strength. As concrete compressive strength increased, GFRP profile effect in hybrid samples decreased. 
Aydın / Anadolu Univ. J. of Sci. and Technology - A - Appl. Sci. and Eng. 17 (3) - 2016

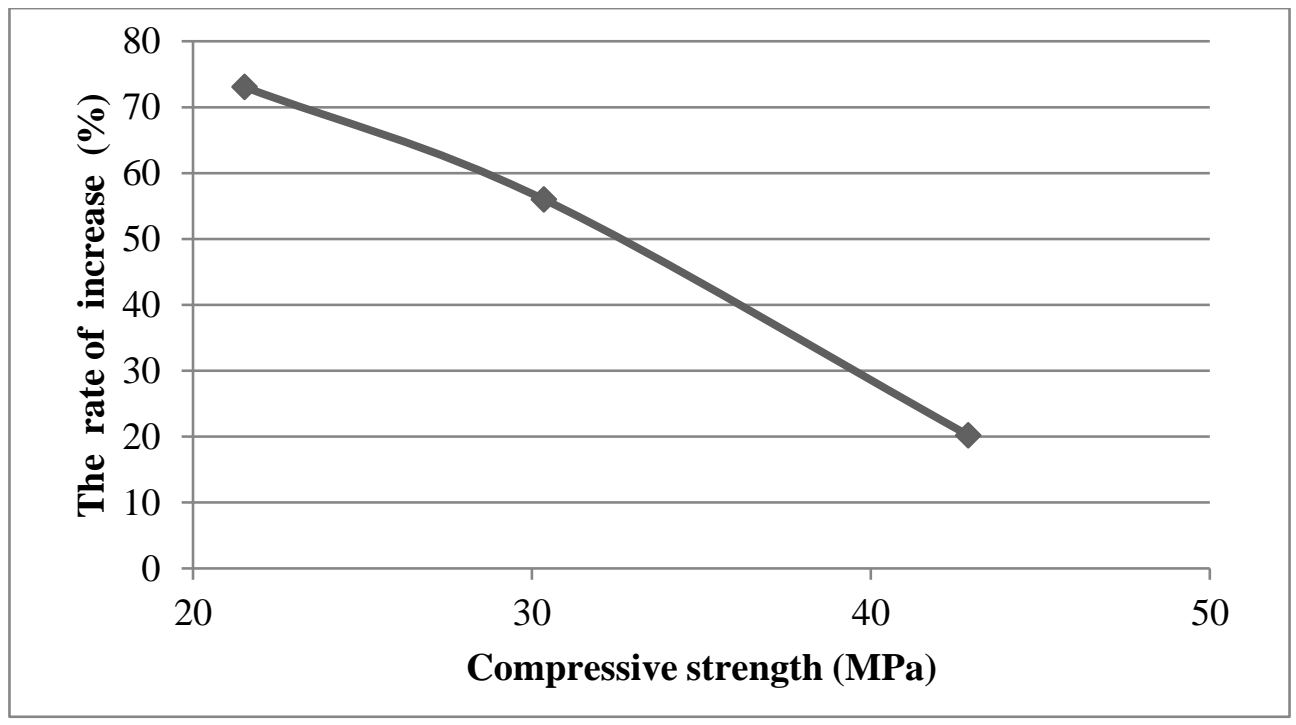

Figure 10. The rates of strength difference in compressive strength

Typical failures of the hybrid samples are shown in Fig. 11. In all specimens, failure resulted from the rupture of the GFRP profiles corner. GFRP profiles were deformed from lateral fibers.

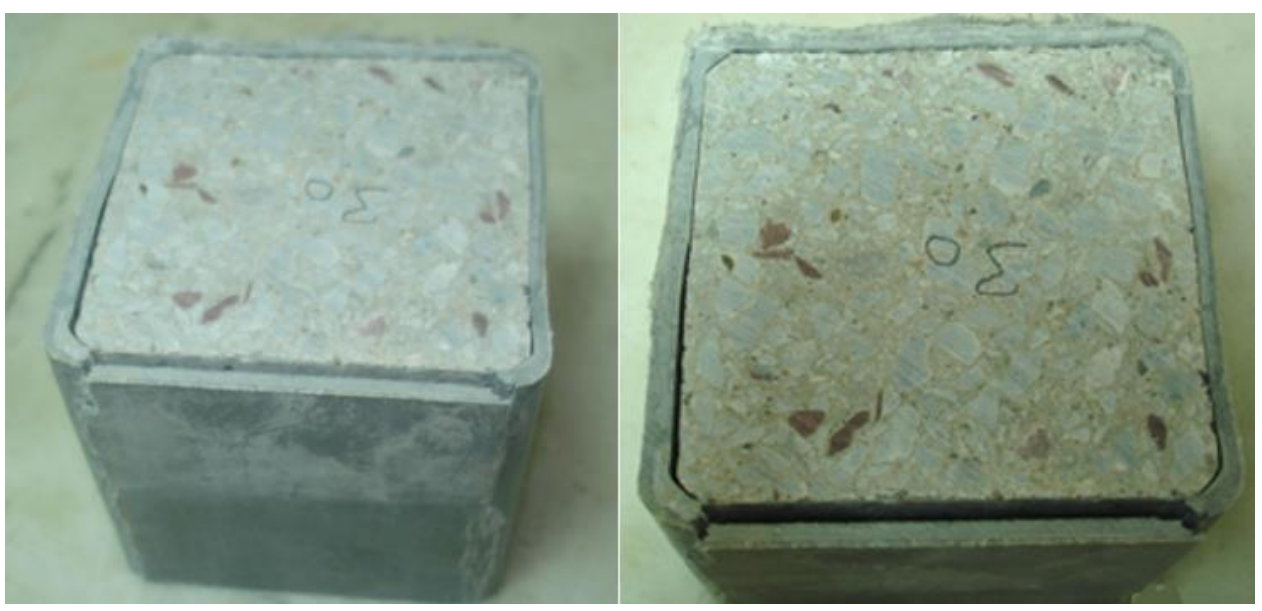

Figure 11. Failure modes of hybrid samples

GFRP profile make up of $14.80 \mathrm{~cm}^{2}$ of total cross section area in hybrid samples. A compressive strength increase of $20-73 \%$ occurred in design of hybrid materials when compared to plain concrete samples. This increase was obtained by $14.8 \%$ GFRP profile in cross-section area. On the other hand, the tests showed that GFRP profiles deformed in felt fibers.

\section{CONCLUSIONS}

The results of this study, which analyzed the behavior of hybrid construction material which used a combination of concrete and GFRP box profiles under compressive strength, are summarized below:

- GFRP profiles have the potential to solve various material related problems in construction sector due to their lightweight structure, high corrosion and tensile strength.

- In hybrid design, since GFRP box profiles serve as formwork, there is no need for a second 
formwork element to form the concrete. GFRP profiles protect the concrete by preventing exterior water and humidity entrance and significantly contribute to concrete curing.

- In compression tests, it was found that compressive strength of hybrid samples in I. strength class increased by $74 \%$ when compared to those of plain concrete samples which had the same cross-section properties. This increase was found to be $52 \%$ in II. strength class and $20 \%$ in III. strength class.

- It was found that as compressive strength class increased, the strength difference between hybrid and plain concrete cube samples decreased. While increase ratio of hybrid samples was $74 \%$ when compared to plain concrete samples at low strengths, as strength class increased, increase ratio decreased. Increase ratio decreased to $20 \%$ at $43 \mathrm{MPa}$. As concrete compressive strength increased, the effect of GFRP profile in hybrid samples decreased.

- In all strength classes, while compressive strength of hybrid samples increased when compared to plain concretes, the weight of hybrid cube samples decreased by $5 \%$ when compared to plain concretes.

- The new hybrid material has a potential to solve the problems of durability and corrosion especially in marine buildings as an independent structure in addition to its high tensile and compressive strength. Furthermore, GFRP-Concrete hybrid construction elements can be used in buildings such as chemical production plants, bridge beams and jetties.

- GFRP profiles deformed in widthwise felt fibers in all tests conducted within the scope of the study. It is foreseen that increasing the ratio of widthwise felt fibers and decreasing lengthwise felt fibers in production process will yield positive results in terms of cost and strength.

\section{REFERENCES}

[1] Aydın, F. and Sarıbıyı, M. Investigation of flexural behaviors of hybrid beams formed with GFRP box section and concrete. Construction and Building Materials. 2013; 41:563-569.

[2] Aydın, F. Investigation of Flexural Behavior of GFRP-Concrete-Steel Fiber Hybrid Beams. International Construction Congress. 11-13 October 2012; Isparta/ Turkey.

[3] Won J.P., Yoon Y.N., Hong B.T., Choi T.J., Lee S.J. Durability characteristics of nano-GFRP composite reinforcing bars for concrete structures in moist and alkaline environments. Compos Struct; 2012; 94:1236-42.

[4] Gonilha, J.A, Correia J.R, Branco, F.A. Dynamic response under pedestrian load of a GFRPSFRSCC hybrid footbridge prototype: experimental tests and numerical simulation. Compos Struct; 2013; 95:453-63.

[5] He, J., Liu Yuqing, Chen, A., Dai, L. Experimental investigation of movable hybrid GFRP and concrete bridge deck. Constr Build Mater; 2012; 26:49-64.

[6] Cripps, A. Fiber Reinforced Polymer Composites in Construction, Construction Industry Research \& Information Association (CIRIA), 2002.

[7] Ayman, M. Composites: Construction Materials for the New Era, Advance Polymer Composites for Structural Applications in Construction (ACIC), 2004; pp. 45-58.

[8] Bank, L.C. Application of FRP Composites to Bridges in the USA. Proceedings of the International Colloquium on Application of FRP to Bridges. 2006; Tokyo, Japan.

[9] Emmons, P.H., Vaysburg, A. M. and Thomas, J. Strengthening of Concrete Structures. Part II. Advanced Composites. ACI Concrete International. 1998; Vol. 20, No. 4, pp. 56-60. 
[10] Weijian, Y. and Hung, H. Experimental Study on The Flexural Behavior of Beams Strengthened with CFRP Laminates. Proc. of the International Conference on FRP. Composites in Civil Engineering. Hong Kong, China. 2001; 12-15. pp. 399-405.

[11] Koksal, H.O. Doran, A. and Turgay, T. A Practical Approach for Modeling FRP Wrapped Concrete Columns. Construction and Building Materials. 2009; 23(3):1429-1437.

[12] Clarke, JL. Strengthening Concrete Structures with Fibre Composites, Struct Build; 2003; 156(1):49-50.

[13] Teng, J.G., Chen, Jf, Smith, St., Lam, L. FRP Strengthened RC Structures. John Wiley, 2002.

[14] Adi, M.N.S. Behaviour of FRP Wrapped Normal Strength Concrete Columns Under Eccentric Loading. Composite Structures. 2006; 72:503-511.

[15] Karbhari, V.M. Durability of Advanced Polymer Composites in the Civil Infrastructure, Advance Polymer Composites for Structural Applications in Construction (ACIC). 2004; pp.31-38.

[16] Hota, V.S. G., Vijay, P.V. and Narendra, T. Reinforced Concrete Design with FRP Composites. CRC Press, 2007.

[17] Hong, W.K., Kim, H.C. and Yoon, S.H. Experiment of Compressive Strength Enhancement of Circular Concrete Column Confined By Carbon Tubes. KCI Concrete Journal 2002; 14:4. 19-144.

[18] Yu T., Wong, Y.L., Teng, J.G., Dong, S.L. and Lam, E.S.S. Flexural Behavior of Hybrid FRPConcrete-Steel Double-Skin Tubular Members. Journal of Composites for Construction. ASCE 2006; pp. 443-452.

[19] Becque, J., Patnaik, A. K. and Rizkalla, S. H. Analytical Models for Concrete Confined With FRP Tubes. J. Compos. Constr., 2003; 7-1:31-38.

[20] Fam, A.Z. and Rizkalla. S.H., Confinement Model for Axially Loaded Concrete Confined by Circular FRP Tubes. ACI Structural Journal. 2001; 98(4):251-461.

[21] Mirmiran, A. and Shahawy. Behavior of Concrete Columns Confined by Fiber Composites. J. Struct. Eng. 1997; 123: 583-590.

[22] Bank, L.C.. Composites for Construction Structural Design with FRP Materials. Wiley, New Jersey, 2006.

[23] Hollaway, L.C. Advance Polymer Composites and Polymers in the Civil Infrastructure. Elsevier Science, First edition, 2001.

[24] Fam, A., Schnerch, D. and Rizkalla, S. Rectangular Filament-Wound Glass Fiber Reinforced Polymer Tubes Filled with Concrete under Flexural Axial Loading: Experimental Investigation. Journal of Composites for Construction. 2005; Vol. 9, No. 1.

[25] Schaumann, E. Hybrid FRP-Lightweight Concrete Sandwich System for Engineering Structures. $\mathrm{PhD}$ thesis. 2008.

[26] Halliwell, S.M. and Reynolds, T. Effective Use of Fibre Reinforced Polymer Materials in Construction. BRE Centre for Composites in Construction. London, 2004. 
Aydın / Anadolu Univ. J. of Sci. and Technology - A - Appl. Sci. and Eng. 17 (3) - 2016

[27] ASTM D 3171-09. Standard Test Methods for Constituent Content of Composite Materials. ASTM (American Society for Testing and Materials), 2009.

[28] ASTM D 3039 M-08. Standard Test Method for Tensile Properties of Polymer Matrix Composite Materials. ASTM (American Society for Testing and Materials), 2007.

[29] TS EN ISO 527-4. Plastics - Determination of tensile properties - Part 4: Test conditions for isotropic and orthotropic fibre-reinforced plastic composites. Turkish Standards Institution, 2007.

[30] TS EN ISO 527-5. Plastics - Determination of tensile properties - Part 5: Test conditions for unidirectional fibre-reinforced plastic composites. Turkish Standards Institution, 2010.

[31] TS 3323. Concrete-Making, accelerated curing and testing concrete compression test specimens. Turkish Standards Institution, 2012.

[32] TS 1247. Mixing, Placing and Curing of Concrete (Normal Weather Conditions). Turkish Standards Institution, 1984. 